\title{
Correction
}

\section{Correction: Cane et al., The Relationship between PSD-95 Clustering and Spine Stability In Vivo}

For the article "The Relationship between PSD-95 Clustering and Spine Stability In Vivo" by Michele Cane, Bohumil Maco, Graham Knott, and Anthony Holtmaat, which appeared on pages 2075-2086 of the February 5, 2014 issue, the authors wish to make two corrections.

1. In the Introduction, on page 2075, two references were erroneously omitted. The correct sentence is: Imaging studies in vivo have shown that proxies for synapses, such as dendritic spines (Trachtenberg et al., 2002) and axonal boutons (De Paola et al., 2006) appear and disappear over days, even in naive mice.

2. In the last paragraph of the Results, on page 2083, the natural logarithm-values were presented instead of the common logarithm values (as stated). The values should be as follows:

Related to Figure 7B: Persistent (always present): PSD-95-eGFP, $-0.021 \pm 0.006$; DsRedExpress, $-0.001 \pm 0.005$; New (gained): PSD-95-eGFP, $0.028 \pm 0.018$; DsRedExpress, $0.028 \pm$ 0.014; Lost: PSD-95-eGFP, $-0.152 \pm 0.042$; DsRedExpress, $-0.115 \pm 0.031$.

Related to Figure 7C: Persistent (always present): PSD-95-eGFP, $0.170 \pm 0.004$; DsRedExpress, $0.135 \pm 0.003$; New (not present at the beginning): PSD-95-eGFP, $0.232 \pm 0.025$; DsRedExpress, $0.212 \pm 0.021$; Lost (present at the beginning but not at the end): PSD-95eGFP, $0.209 \pm 0.012$; DsRedExpress, $0.165 \pm 0.010$.

These corrections do not affect the main conclusions and interpretations of the paper. Figure 7 and the related statistics remain unchanged.

\section{References}

De Paola V, Holtmaat A, Knott G, Song S, Wilbrecht L, Caroni P, Svoboda K (2006) Cell type-specific structural plasticity of axonal branches and boutons in the adult neocortex. Neuron 49:861-875. CrossRef Medline

Trachtenberg JT, Chen BE, Knott GW, Feng G, Sanes JR, Welker E, Svoboda K (2002) Long-term in vivo imaging of experience-dependent synaptic plasticity in adult cortex. Nature 420:788-794. CrossRef Medline

DOI:10.1523/JNEUROSCI.1278-14.2014 